\title{
Linear and whorled hyperpigmentation: A case of incontinentia pigmenti with dermoscopic features
}

\author{
(1) Omer Faruk Elmas, ${ }^{1}$ (1) Asuman Kilitci, 2 ㄴ) Necmettin Akdeniz ${ }^{3}$ \\ ${ }^{1}$ Department of Dermatology, Ahi Evran University Faculty of Medicine, Kirsehir, Turkey \\ 2Department of Pathology, Ahi Evran University, Faculty of Medicine, Kirsehir, Turkey \\ ${ }^{3}$ Department of Dermatology, Istanbul Medeniyet University, Faculty of Medicine, Istanbul, Turkey
}

Cite this article as: Elmas OF, Kilitci A, Akdeniz N. Linear and whorled hyperpigmentation: A case of incontinentia pigmenti with dermoscopic features. North Clin Istanb 2021;8(1):95-96.

A 13 months old girl was referred to our dermatology department with a complaint of asymptomatic generalized brown discoloration over the body for six months. The parents first noticed vesicular lesions over the trunk and extremities at birth, and these lesions turned into linear hyperpigmentation months later. Dermatological examination revealed few papulovesicular lesions and linear and whorled brownish hyperpigmentation following Blaschko lines over the chest and back (Fig. 1). The extremities were less involved. On dermo-
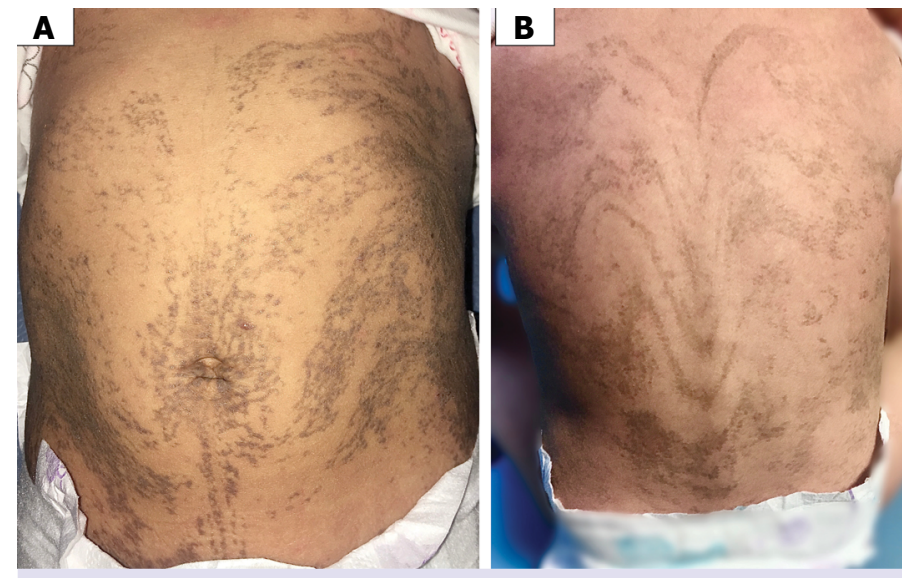

FIGURE 1. Linear and whorled brownish hyperpigmentation following Blaschko lines over the chest, abdomen (A) and back (B). scopic examination, patchy distribution of brownish reticular lines and curved lines, dots and clods over a light brown background were detected (Fig. 2). Histopathological examination showed basal vacuolar degeneration and dermal melanin deposition in melanophages. Based on the clinical and histopathological findings, a diagnosis of Stage 3 Incontinentia pigmenti was made. No periodontal, neurologic and ocular involvement was detected. Periodic dental, dermatological, neurologic and ophtalmologic examinations were recommended.
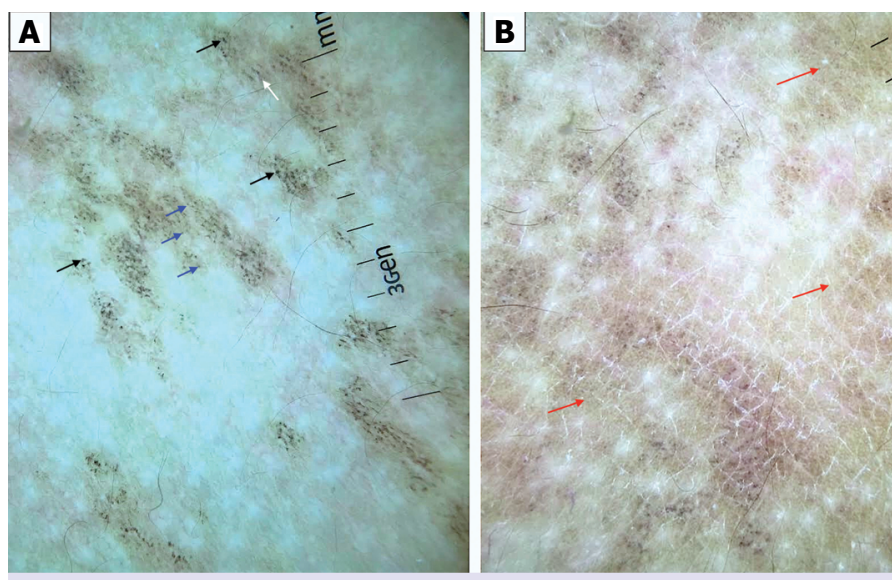

FIGURE2. (A) Curved lines (white arrows), dots (blue arrows) and clods (black arrows) over a light brown background. (B) Patchy distribution of brownish reticular lines (red arrows). 
Incontinentia pigmenti is a very rare $\mathrm{X}$ - linked neuroectodermal disorder caused by IKBKG (formerly known as NEMO) gene defect. The entity is often lethal in males, but females survive due to $\mathrm{X}$-inactivation mosaicism [1].

Incontinentia pigmenti can be identified by characteristic cutaneous findings, a chronology of four stages that occurs during the first year of life. Central nervous system and eye involvement may cause disability. Hair, nails and teeth may also be involved [1]. Our patient demonstrated no sign of systemic involvement.

The differential diagnosis mainly includes linear and whorled nevoid hypermelanosis (LWNH), hypomelanosis of Ito, linear epidermal nevus. Typical chronology of incontinentia pigmenti is usually a strong clue to the diagnosis. The other entities entering the differential diagnosis does not show this unique chronology.

Dermoscopy is a non-invasive practical tool being increasingly used in the diagnosis of skin diseases. Dermoscopic features of many cutaneous conditions have been well described. However, to our knowledge, dermoscopic features of incontinentia pigmenti have never been described in the relevant literature. In our case, dermoscopic features identified were patchy distribution of brownish reticular lines and, curved lines, dots and clods over a light brown background. Dermoscopy of LWNH, which can be considered one of the major differentials of incontinentia pigmenti, has been described in a case report as "antler-like brown pigmen- tation", which is quite different from the pigmentation pattern we observed in our patient [2].

Epidermal nevus usually has an elevated and verrucous surface in contrast to incontinentia pigmenti. However, flat or slightly elevated lesions of epidermal nevus should be considered in the differential diagnosis. Dermoscopic features of slightly elevated epidermal nevus includes branched thick brown lines, brown dots forming lines and serpiginous brown dots [3]. These features are also pretty different from what we observed in the present case.

Although more studies are needed to clarify dermoscopic findings of incontinentia pigmenti, we suggest that dermoscopic examination may provide an additional clue to the diagnosis.

Informed Consent: Written informed consent was obtained from the patient for the publication of the case report and the accompanying images.

\section{REFERENCES}

1. Greene-Roethke C. Incontinentia Pigmenti: A Summary Review of This Rare Ectodermal Dysplasia With Neurologic Manifestations, Including Treatment Protocols. J Pediatr Health Care 2017;31:e45-52.

2. Ito T, Yoshida Y, Goto H, Furue M, Yamamoto O. Linear and Whorled Nevoid Hypermelanosis With Tetralogy of Fallot. Indian J Dermatol 2015;60:325. [CrossRef]

3. Elmas ÖF, Akdeniz N. Dermoscopic aspect of verrucous epidermal nevi: new findings. Turk J Med Sci 2019;49:710-4. [CrossRef] 